\title{
Promotional Tools Effect on Pharmaceuticals Marketing
}

\author{
Post Raj Pokharel ${ }^{1^{*}}$
}

\begin{abstract}
This paper shows the effect of promotional tools on pharmaceuticals marketing. The study is based on survey method using marketing field force and their opinion in relation to the promotional tools used in pharmaceuticals marketing. This study which is primarily descriptive focuses on finding out tools used as promotional devices and their significance on marketing. The study shows that doctors detailing is the most effective tools used as promotional tool and has most significant effect on marketing. Use of product sample has also significant effect on marketing subsequent to the doctors detailing. In addition to that, pharmaceuticals' marketing has been positively influenced by the corporate presence in different health related activities like CME programs, health camps where multiple promotional effects have been made. CME programs and health camps tools have been more successful in effective marketing especially on specialty products like: anti-diabetics, anti-psychiatric, and cardiac products etc.
\end{abstract}

\section{JEL Classification: M31.}

\section{Key Words: Pharmaceuticals Marketing, Promotion.}

\section{Introduction}

The market for pharmaceuticals is one of the most highly regulated markets in the country. Nepal's Drugs Act, 2035, (1978) section 19 has prohibited advertisements about the use, utility or efficacy of any drug without the consent or obtaining the license, as prescribed, from the Department, by paying the fees prescribed for the same. Looking at the US history of promotion of pharmaceuticals products between 1980 and 2010, expenditures on prescription (Rx) drugs increased from \$53 per person to \$831 per person, representing an increase of $1,468 \%$.

Pharmaceutical marketing is the business of advertising or otherwise promoting the sale of pharmaceuticals or drugs. Marketing plays a key role in influencing or directing activities from the manufacturer to the patient. It is the demand from the consumer that determines which goods will be produced. Any pharmaceutical company that wants to serve its market has to endeavour in direct marketing activities so that the right product is sold in the right quantity in the right place at the right time.

According to Lidstone (1999), the aim is to change from a non-usage of a product to usage or repeated usage. There are different buying stages of healthcare professionals in which the pharmaceutical companies have to make their product known using techniques like : (a) unawareness to awareness -in which the medicinal drug moves from no knowledge towards a situation where the healthcare professional knows about it, (b) awareness to interest- here the healthcare professional will have his curiosity motivated by the products' newness, appearance, or concept, (c) interest to evaluation, under which the professional will consider the effect of the product upon his motivations i.e. lifestyle or image. The healthcare professional

1 Faculty at Boston International College, Bharatpur 
will analyze, rationalize, and look for advantages with the new product depending on what the healthcare professional needs, such as improved efficacy, more economy, the uniqueness of the drug and safety, (d) evaluation to trial, in which he/she is still considering the product to actually use it. Marketing from the company at this stage has to identify usage opportunities and Suggest the usage when the opportunities occur, (e) trial to usage, under this stage, the professional will move to usage in prescribing the product. The pharmaceutical company at this point has to provide reminders of key elements such as brand, therapy area and the advantages of usage, (f) usage to repeat usage-this is the final objective for marketing. When a healthcare professional moves from the occasional use to constant use, they move into a stage of automatically selecting the particular prescription drug. At this stage the company has to maintain the environment that has led to satisfaction, keep a satisfactory image and keep confirming and reminding the healthcare professional of the key qualities of the product.

During these stages of marketing a drug, pharmaceutical companies in their pursuit of increased profits, can use unethical methods to push their products. From the first stage of introducing the product, right through the final stage of usage to repeated usage, the company will try to influence the healthcare professionals choice in choosing their particular product.

The contemporary pricing techniques and the pharmaceuticals marketing practices combined together to influence the prescribing products. Pokharel, (2015) study on contemporary pricing policy of Nepalese Pharmaceuticals products showed strong variations in pricing of the pharmaceuticals products, the practice of pricing of the products was found reference-based and comparative pricing technique. The study also identified that the product bonus culture, discount policy and promotional campaigning have influenced the pricing decision rather than cost of production. Pokharel (2015) also puts special focus on the significance of inflation, interest rate and the exchange rate fluctuation have been the matter of study that has impact on pricing of the pharmaceuticals products.

\section{Methodological Aspects}

A survey questionnaire was distributed to the medical representative and managers including first line managers and regional managers of 20 different companies including both the Nepalese and Indian companies together with their divisions in which total respondents were 65. A set of questionnaire was sent through online- facebook and e-mail -and also 20 medical representatives were informed through telephone to fill the questionnaire and send back through e-mail.

The questionnaire consisted of free opinion based questions. Initially questionnaire including close-ended questions were sent but due to data filling problem from the respondents free opinion based questionnaire were sent with addition of requesting to mention the additional tools used and their significance on marketing of their products. The first question of the questionnaire was devoted to obtaining information on the respondents of the companies surveyed. The responses are presented in Table 1A-1B. As is evident 
from Table $1 \mathrm{~A}$, the majority of the persons responding to the survey $(73.85 \%)$ hold the position of medical representative and there is also a satisfactory number holding the position of first line manager $(23 \%)$ and regional sales manager (3\%). With respect to experience working in pharmaceuticals marketing, $63 \%$ of the respondents covered by the study are having 1 to 3 years experience, $17 \%$ are of 3 to 5 years experience, $11 \%$ are of 5 to 7 years experience, $6 \%$ are of Less than 1 year experience and the rest are more than 7 years experience.

Table 1: Respondents' Profile

A: Respondents' Position in the Pharmaceuticals Company

\begin{tabular}{|l|c|c|}
\hline \multicolumn{1}{|c|}{ Position } & Number & Percentage \\
\hline Regional Sales Manager & 2 & 3 \\
\hline First Line Manager & 15 & 23 \\
\hline Medical Representatives & 48 & 74 \\
\hline Total & $\mathbf{6 5}$ & $\mathbf{1 0 0}$ \\
\hline
\end{tabular}

B: Respondent's Experience Working in Pharmaceuticals Marketing

\begin{tabular}{|l|c|c|}
\hline \multicolumn{1}{|c|}{ Years of Experience } & Number & Percentage \\
\hline Less than 1 & 4 & 6 \\
\hline 1 to 3 & 41 & 63 \\
\hline 3 to 5 & 11 & 17 \\
\hline 5 to 7 & 7 & 11 \\
\hline More than 7 & 2 & 3 \\
\hline Total & $\mathbf{6 5}$ & $\mathbf{1 0 0}$ \\
\hline
\end{tabular}

\section{The Results}

\section{A. Tools for Pharmaceuticals Marketing}

The main aim of the survey was to identify the marketing tools used as promotion of pharmaceuticals products. Respondents were given to select 10 closed-end promotional tools but only seven promotional tools were found selected. The rejection of promotional tools like: Public Advertising through media, use of posters, banners, pamphlets. Table 2 shows 7 different promotional tools from 65 observations with their significant out of $100 \%$ on marketing. 
Table 2. Tools used for pharmaceuticals marketing as promotion and their significant

\begin{tabular}{|c|l|c|}
\hline S.No. & Promotional Tools & Significant (Out of 100\%) \\
\hline 1. & Doctors detailing & $33 \%$ \\
\hline 2. & Product sample distribution & $16 \%$ \\
\hline 3. & Stockiest Incentive & $2 \%$ \\
\hline 4. & Cash Discount & $5 \%$ \\
\hline 5. & Gift to Doctors, chemist, stockiest & $14 \%$ \\
\hline 6. & Sponsoring schemes to doctors & $12 \%$ \\
\hline 7. & CME programs, Health Camps & $18 \%$ \\
\hline Total & & $100 \%$ \\
\hline
\end{tabular}

Table 2. has been presented to justify the aim of the survey in which doctors detailing was prominent as the major promotional tools used in pharmaceuticals marketing (33\%), subsequently CMEs (18\%), product sample distribution (16\%), gift to doctors, chemist and stockiest (14\%), sponsoring scheme to doctors $(12 \%)$. The another way of promoting products i.e. cash discount and stockiest incentive was least $5 \%$ and $2 \%$ respectively. The effectiveness of quality pharmaceuticals marketing is found personal relationship i.e. represented by doctors detailing and CME programs and health camps. This is specialty because of health related marketing of pharmaceuticals products.

Table No. 3. Marketing Personnel View on Indirect Promotional Tools for Pharmaceuticals Marketing

\begin{tabular}{l|l}
\hline S.No. & Indirect Promotional Tools \\
\hline 1. & Product Bonus \\
2. & Lot Bonus \\
3. & Extra Bonus as Adjustment \\
4. & Invoicing at Institutional Rate \\
\hline & Source: Primary Data Sheet
\end{tabular}

Respondents were requested to write their open view on any indirect promotional tools that was in practice in the pharmaceuticals marketing. The remarks of the respondents are consistent with regard to contemporary pricing practices in their companies and other companies too. Marketing personnel view on applying indirect way of promoting corporate products was a little bit different from that of direct methods. The way to using product bonus, lot bonus, extra bonus was surprisingly used in order to lubricate additional sales indirectly. This type of tools sometimes been experienced by marketing teams as switching policy and used especially for general products in which normal medical practitioners refer the general products. Marketing personnel response on using indirect method has been unethically practicing by some companies but has been rationally being in practice at Time Pharmaceuticals P. Ltd. as they comply with the established marketing policy. 


\section{Promotional Expenses Trend}

Respondents were asked to note down the relationship between promotional expenses and sales of last 10 years data. Some respondents deny presenting the figure in amount and provided in growth \% format. In order to make uniform to all the data set, \% growth of promotional expenses and \% growth of sales have been calculated and compared with trend line from FY 2061/62 to FY 2070/71.

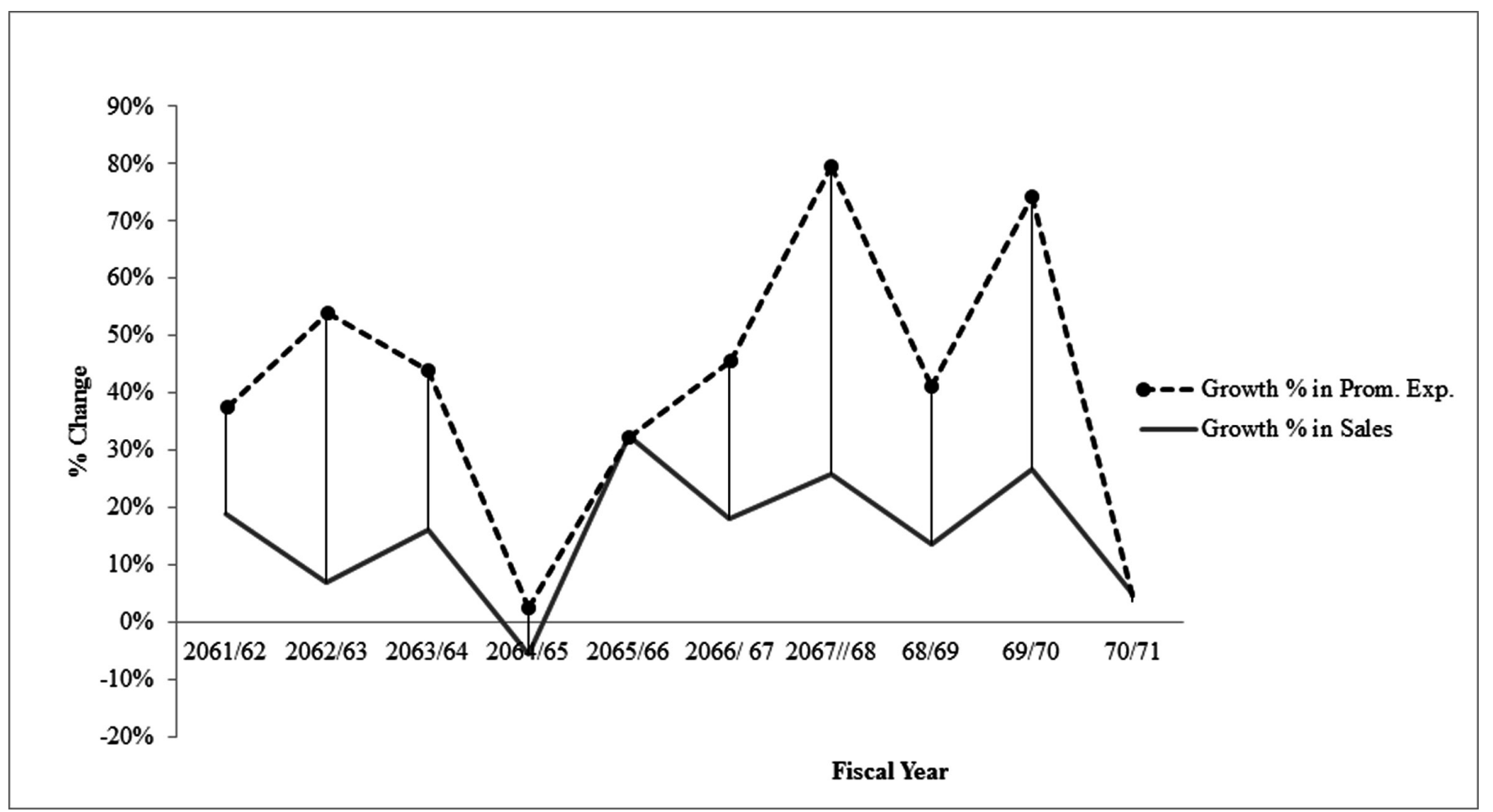

Figure No. 1: Line chart of \% change in promotional expenses and \% change in sales Source: Annual Report of Time Pharmaceuticals P. Ltd. from FY 2061/62 to 2070/71

The trend of change in sales and subsequently change in promotional expenses in comparison to the previous years showed that the change deviation has been observed between the two variables in response to previous years.

Table No. 6.2: Correlation coefficient between sales and profit

\begin{tabular}{|l|r|r|r|}
\hline & Sales (Rs.) & Prom. Exp (Rs.) & Profit (Rs.) \\
\hline Sales (Rs.) & 1 & 0.99 & 0.49 \\
\hline Prom. Exp (Rs.) & & 1.00 & 0.43 \\
\hline Profit (Rs.) & & & 1 \\
\hline
\end{tabular}

The correlation coefficient between sales and profit shows that company is increasing profit revenue as sales increases and this is the most positive signal to the company as it has to make massive growth on sales for the purpose of maximum profit generation. 


\section{Conclusion}

The survey study was concerned with effect of promotional expenses on pharmaceuticals marketing of Time Pharmaceuticals P. Ltd, a sample company. It used both primary and secondary data. The main objective was to identify the promotional status of Time Pharmaceuticals P. Ltd focusing on the major areas of promotion, promotional activities on marketing of Pharma Products at Time Pharmaceuticals P. Ltd and also on examination of the sensitive of promotional scheme on marketing. The method of analysis is descriptive. The study shows that among the applied promotional tools, doctors detailing is the most effective tools used as promotional tool and has most significant effect on marketing. Use of product sample has also the significant effect on marketing subsequent to the doctors detailing. In addition to that, pharmaceuticals' marketing has been positively influenced by the corporate presence in different health related activities like CME programs, health camps where multiple promotional effects have been made. CME programs and health camps tools were found to be more successful in effective marketing especially on specialty products like: anti-diabetics, anti-psychiatric, and cardiac products etc.

\section{References}

Drugs Act (2035). http://dda.gov.np/files/Drugs_Act_2035.pdf The Drugs (Second Amendment) Act, 2057 (2000) 2057.8.14 (29 November 2000)

Pokharel, P.R. (2015). A Survey of Contemporary Pricing Policy: Nepalese Pharmaceuticals Products. Peer Review Process. Manuscript Accepted Pokhara University

Lidstone, J. MacLennan, J. (1999). Marketing Planning for the Pharmaceutical Industry, (2nd ed.) Gower Publishing.

SK and A. (2011). U.S. Pharma Company Promotion Spending. Cegedim Strategic Data Report, http://www.skainfo.com/, February 2012.

Time Pharmaceuticals (2071 BS). Annual Report from FY 2060/61 to FY 2070/71 